\title{
The Clinical Efficacy and Safety of Four- Weekly Docetaxel as First-Line Therapy in Elderly Lung Cancer Patients with Squamous Cell Carcinoma
}

\author{
Jong Hyun Choi, M.D. ${ }^{1}{ }^{\circledR}$, Juwhan Choi, M.D. ${ }^{1}$, Sang Mi Chung, M.D. ${ }^{1}$, Jee Youn Oh, M.D., Ph.D. ${ }^{1}$,

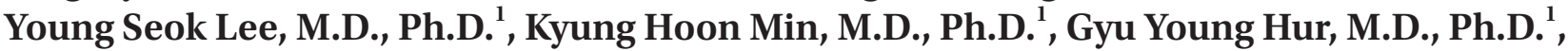 \\ Jae Jeong Shim, M.D., Ph.D. ${ }^{1}$, Kyung Ho Kang, M.D., Ph.D. ${ }^{1}$, Hyun Kyung Lee, M.D., Ph.D. ${ }^{2}$ and \\ Sung Yong Lee, M.D., Ph.D. ${ }^{1}$ (iD \\ ${ }^{1}$ Department of Internal Medicine, Korea University Guro Hospital, Seoul, ${ }^{2}$ Department of Internal Medicine, Inje University \\ Busan Paik Hospital, Busan, Korea
}

\begin{abstract}
Background: Docetaxel is one of the standard treatments for advanced non-small cell lung cancer. Docetaxel is usually administered in a 3-week schedule, but there is significant toxicity. In this phase II clinical study, we investigated the efficacy and safety of a 4-weekly schedule of docetaxel monotherapy, as first-line chemotherapy for advanced squamous cell carcinoma in elderly lung cancer patients.

Methods: Patients with stage IIIB/ IV lung squamous-cell carcinoma age 70 or older, that had not undergone cytotoxic chemotherapy were enrolled. Patients received docetaxel $25 \mathrm{mg} / \mathrm{m}^{2}$ on days 1,8 , and 15 , every 4 weeks. Primary endpoint was the objective response rate (ORR). Secondary endpoints were progression-free survival (PFS), overall survival (OS), and toxicity profiles.

Results: A total of 19 patients were enrolled. Among 19 patients, 17 were for evaluated efficacy and safety. In the intentto-treat population, ORR and disease control rate (DCR) were $11.8 \%$ and $47.1 \%$, respectively. In the response evaluable population, ORR was $16.7 \%$ and DCR was $66.7 \%$. Median PFS and OS were 3.1 months and 3.3 months, respectively. There were three adverse grade 3/4 events. Grade 1 neutropenia was reported in one patient.

Conclusion: Our data failed to demonstrate efficacy of a 4-weekly docetaxel regimen, in elderly patients with a poor performance status. However, incidence of side effects, including neutropenia, was lower than with a 3-week docetaxel regimen, as previously reported.
\end{abstract}

Keywords: Carcinoma, Non-Small-Cell Lung; Chemotherapy; Docetaxel; Treatment Outcome; Safety; Therapeutics; Aged; Lung Neoplasms; Carcinoma, Squamous Cell

\section{Address for correspondence: Sung Yong Lee, M.D., Ph.D. \\ Department of Internal Medicine, Korea University Guro Hospital, 148 \\ Gurodong-ro, Guro-gu, Seoul 08308, Korea \\ Phone: 82-2-2626-3030, Fax: 82-2-2626-1166 \\ E-mail: syl0801@korea.ac.kr \\ Received: May. 30, 2018 \\ Revised: Sep. 15, 2018 \\ Accepted: Oct. 12, 2018 \\ Published online: Dec. 20, 2018 \\ (c) It is identical to the Creative Commons Attribution Non-Commercial License (http://creativecommons.org/licenses/by-nc/4.0/).}

\section{Introduction}

In the past, the first-line chemotherapy for non-small cell lung cancer (NSCLC) included a platinum-based doublet regimen ${ }^{1-3}$. In recent decades, there has been great progress in the treatment of lung cancer. In particular, molecular-targeted agents, including epidermal growth factor receptor (EGFR) tyrosine kinase inhibitors (TKI) or anaplastic lymphoma kinase inhibitors, have been reported to show significantly improved survival and reduced toxicity ${ }^{4}$. For the advanced non-squamous NSCLC, pemetrexed and cisplatin followed by maintenance pemetrexed regimen have shown good clinical efficacy. Furthermore, immune checkpoint inhibitors 
targeting programmed death- 1 or programmed death ligand 1 (PD-L1) have been associated with a greater survival rate in patients with high expression of PD-L1 ${ }^{5-7}$. However, these agents can only be used in selected patients with a driving gene mutation or high PD-L1 expression. Therefore, patients without driving mutations or low PD-L1 expression still need standard cytotoxic chemotherapy, and in particular, elderly patients are often unable to undergo chemotherapy because of their comorbidities and the concern of frequently occurred chemotherapy related serious adverse events.

Docetaxel has been shown to be efficacious as a monotherapy in both chemo-naïve and resistant NSCLC ${ }^{8-10}$ and is approved on a 3-week schedule at a dose of $75 \mathrm{mg} / \mathrm{m}^{2}$. However, severe and frequent myelosuppression was observed on the 3 -week schedule. In phase 1 clinical trials, $100 \mathrm{mg} / \mathrm{m}^{2}$ was administered at 3-week intervals, and grade 3-4 neutropenia was present in more than $90 \%$ of participants ${ }^{11}$. In addition, among the clinical trials conducted in Japan, neutropenia has been reported ${ }^{12}$ in more than $80 \%$ of patients even when administered at a dose of $60 \mathrm{mg} / \mathrm{m}^{2}$.

In a previous clinical trial of NSCLC patients treated with docetaxel on weekly schedules, severe toxicity profiles of neutropenia and febrile neutropenia were improved while retaining the antitumor effect compared with those of a 3-week schedule ${ }^{13,14}$. Based on these results, we evaluated the efficacy and safety of docetaxel alone in 4-weekly schedules as firstline therapy in elderly patients with squamous cell lung carcinoma.

\section{Materials and Methods}

This study was an open-label, single-arm phase II trial. The primary endpoint was the objective response rate (ORR). Secondary endpoints included progression-free survival (PFS), overall survival (OS), and safety profiles.

\section{Study design and participants}

Chemotherapy-naïve patients aged 70 years or older with measurable, histologically confirmed advanced squamous cell NSCLC classified as clinical stage IIIB or IV (American Joint Committee on Cancer seventh edition) and with an Eastern Cooperative Oncology Group performance status (ECOG PS) of $1-2$ were enrolled in the study.

In addition, patients were required to satisfy the following criteria: absolute neutrophil count $\geq 1,500 / \mathrm{mm}^{3}$, platelet count of $\geq 100,000 / \mathrm{mm}^{3}$, serum total bilirubin level of $\leq 1.25$ times the upper limit of the normal range, serum levels of aspartate aminotransferase and alanine aminotransferase $\leq 3.0$ times the upper limit of the normal range of each institution (if there were liver metastasis, $\leq 5.0$ times the upper limit of the normal range), serum levels of alkaline phosphatase $\leq 2.5$ times the upper limit of the normal range (if there were liver metastasis, $\leq 5.0$ times the upper limit of the normal range), serum creatinine levels of $<1.5 \mathrm{mg} / \mathrm{dL}$, and estimated life expectancy exceeding 3 months.

Patients with other coexisting malignancies, symptomatic brain metastasis, peripheral neuropathy of grade 2 or higher, clinically significant heart disease (e.g., congestive heart failure uncontrolled with medication, symptomatic coronary artery disease, or arrhythmia) or myocardial infarction within 12 months were not enrolled. In addition, patients who received radiotherapy or administered another test drug within 4 weeks of the start of the study were excluded.

All enrolled patients provided written informed consent and the institutional review boards of Korea University Guro Hospital (IRB No. 2011GR0230) and Busan Paik Hospital (IRB No. 10-211) approved the study.

\section{Treatment schedule}

Patients enrolled in the study received $25 \mathrm{mg} / \mathrm{m}^{2}$ docetaxel over 1 hour on days 1, 8, and 15, every 4 weeks. Patients were premedicated with dexamethasone and antihistamine to prevent anaphylactic reactions and emesis.

\section{Response evaluation and safety assessment}

Chest computed tomography was performed every 2 cycles (8 weeks) and when clinical disease progression was suspected. Responses were evaluated as complete remission (CR), partial remission (PR), stable disease (SD), and progressive disease (PD) according to Response Evaluation Criteria in Solid Tumor version $1.1^{15}$. The relative dose intensity (RDI) is the ratio of delivered to the planned dose intensity. An RDI of $100 \%$ indicates that the drug was administered at the dose planned per protocol, without delay and without cancellations.

The safety profile, including monitoring of adverse events (AEs), vital signs, hematology, routine chemistry, and urinalysis, was evaluated. AE severity was graded based on the National Cancer Institute Common Terminology Criteria (NCI CTC) for Adverse Events version 3.0.

\section{Statistical analysis}

The ORR was calculated by the sum of the CR and PR rates and is presented with the $95 \%$ confidence interval $(\mathrm{CI})$. The disease control rate (DCR) was defined as the sum of the CR, PR, and SD rates. PFS was defined as the time from the start of treatment to the point at which PD was confirmed or to the time of death. Patients whose disease had not progressed at the final analysis were censored on the last tumor evaluation date. OS was defined as the time from the start of treatment to the time of death. Follow-up was performed for up to 6 
months after the end of treatment for the surviving patients. Survival analyses were estimated using the Kaplan-Meier method. Safety analyses summarized AEs using NCI CTC version 3.0 during the entire treatment period.

\section{Results}

\section{Patient characteristics}

Nineteen patients were enrolled in the study from two cancer centers in South Korea between July 26, 2011 and May 25, 2015 (Figure 1). Two patients chose to withdraw from the study before they receive docetaxel; therefore, we evaluated efficacy and safety in 17 patients. Patient baseline demographics and clinical characteristics are shown in Table 1. The median age of the patients was 78 years (range, $71-86$ years) and 16 patients (94.1\%) were men; six patients (35.3\%) had stage IIIB and 11 (64.7\%) had stage IV disease; 24\% had an ECOG PS of 2. The majority of patients had a history of smoking (94.1\%). The median forced expiratory volume in 1 second was $1.65 \mathrm{~L}$ (range, $0.80-2.6 \mathrm{~L}$ ).

\section{Efficacy}

In the intent-to-treat population, ORR and the DCR were 11.8 and $47.1 \%$, respectively. For the response evaluable population, response evaluation was performed in 12 patients because five did not have imaging follow-up. The ORR was $16.7 \%$. No patients achieved a CR and two achieved a PR (16.7\%). SD was seen in six patients (50\%) and PD in four (33.3\%) (Table 2). The DCR was $66.7 \%$. The duration of response for patients who achieved a PR was 3.8 months. The median number of cycles was 2 (range, 1-6). The mean relative dose intensity is $54.1 \pm 30.1 \%$ (mean \pm standard deviation). The median PFS was 3.1 months (95\% CI, 2.12-4.08) and the median OS was 3.3 months (95\% CI, 1.33-5.27) (Figure 2 ). The largest percentage changes in the sum of the longest diameters of the target lesions compared with baseline are shown in Figure 3.

\section{Safety}

Of the 17 patients who received docetaxel at any one time, five did not have any AEs. Of the 10 patients who received more than 2 cycles, two did not have any AEs. The overall incidence of grade $\geq 3$ AEs was $17.6 \%$ ( 3 of 17 patients). Grade $\geq 3$ AEs occurred in three patients and included diarrhea (2/17) and dizziness (1/17) (Table 3). Among them, dose reductions

Table 1. Baseline characteristics of patients with lung squamous cell carcinoma

\begin{tabular}{|lc|}
\hline \multicolumn{1}{|c|}{ Characteristic } & Value $(\mathbf{n}=\mathbf{1 7})$ \\
\hline Age, yr & $78(71-86)$ \\
Sex & $16(94.1)$ \\
Male & $1(5.9)$ \\
Female & \\
Stage & $6(35.3)$ \\
IIIB & $11(64.7)$ \\
IV & \\
Performance status & $13(76.5)$ \\
\hline $0-1$ & $4(23.5)$ \\
2 & $1(5.9)$ \\
Smoking history & $11(64.7)$ \\
Never & $5(29.4)$ \\
\hline Former & $52.5(8-100)$ \\
Current & $1.65(0.8-2.6)$ \\
Amounts, pack year & $1.6(1.36-1.93)$ \\
\hline FEV ${ }_{1}$, L & \\
BSA, m ${ }^{2}$ & \\
\hline
\end{tabular}

Values are presented as median (range) or number (\%).

$\mathrm{FEV}_{1}$ : forced expiratory volume in 1 second; BSA: body surface area.

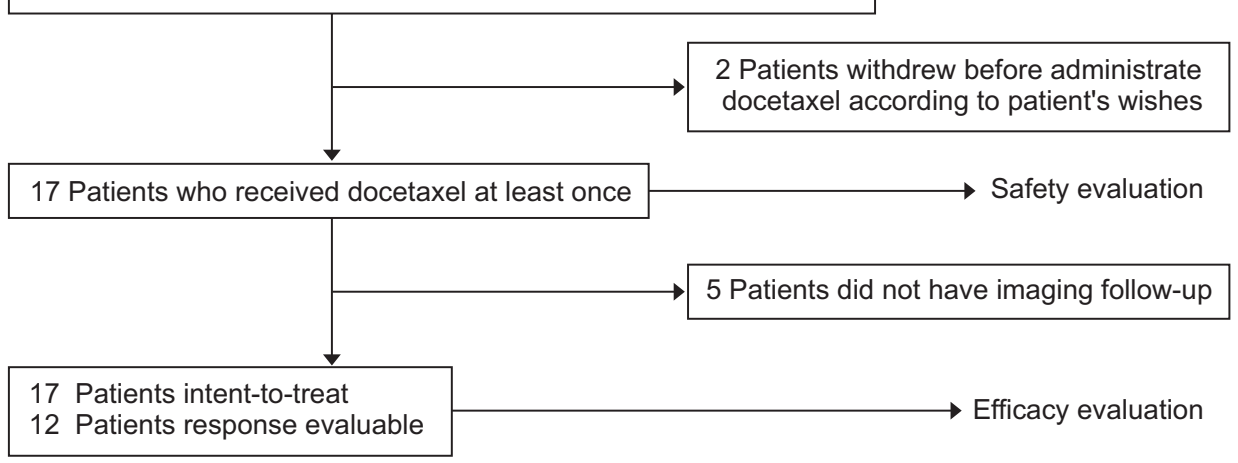


of docetaxel were required in only one patient and the other two withdrew from the study. Neutropenia was reported in only one patient and was grade 1. Fatal events occurred in three cases but were determined to be unlikely to be related to the study drug. Two patients who achieved SD died due to progression of interstitial lung disease diagnosed before the administration of docetaxel. One patient discontinued treatment because of deterioration in their general condition during the second cycle and died 30 days after the last docetaxel administration.

\section{Discussion}

According to a recent report, lung cancer is the leading cause of cancer-related death worldwide in both sexes ${ }^{16}$. Approximately $75 \%$ of lung cancers have non-small cell histology, and most of these are locally advanced stage III or meta-

Table 2. Best objective response

\begin{tabular}{|lcc|}
\hline \multicolumn{1}{c}{ Response } & ITT $(\mathbf{n}=\mathbf{1 7})$ & RE $(\mathbf{n}=\mathbf{1 2})$ \\
\hline CR & $0(0)$ & $0(0)$ \\
PR & $2(11.8)$ & $2(16.7)$ \\
SD & $6(35.3)$ & $6(50.0)$ \\
PD & $4(23.5)$ & $4(33.3)$ \\
NE & $5(29.4)$ & $0(0)$ \\
Overall response rate, \% & 11.8 & 16.7 \\
\hline Disease control rate, $\%$ & 47.1 & 66.7 \\
\hline
\end{tabular}

Values are presented as number (\%) unless otherwise indicated. ITT: intent-to-treat; RE: response evaluable population; CR: complete remission; PR: partial remission; SD: stable disease; PD: progressive disease; NE: not evaluable.

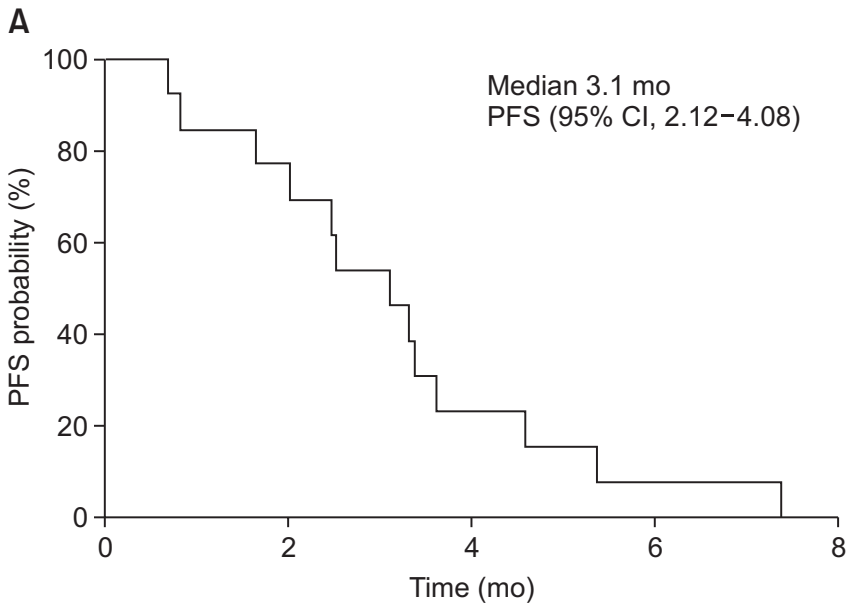

static stage IV when diagnosed ${ }^{5}$. More than half of confirmed advanced NSCLC patients are over 65 years old because they often do not have specific symptoms at an earlier stage ${ }^{17}$. However, well-known large randomized clinical trials have excluded elderly patients and those with a poor PS; therefore, the limited evidence-based data are inadequate to provide proper management for these patients ${ }^{18}$.

For NSCLC patients, platinum-based doublet regimens are basic first-line chemotherapy but are often difficult to use due to toxicity in some elder patient with poor PS. Oral EGFR-TKIs have improved OS and PFS in patients with known EGFRsensitizing mutations in NSCLC over chemotherapy in several clinical studies ${ }^{4}$. However, mutations in the EGFR gene have been shown to be most prominent in the Asia-Pacific adenocarcinoma subgroup ${ }^{19}$. Therefore, patients with nonadenocarcinoma have a relatively limited range of chemotherapeutic options.

Docetaxel is one of the standard chemotherapeutic agents

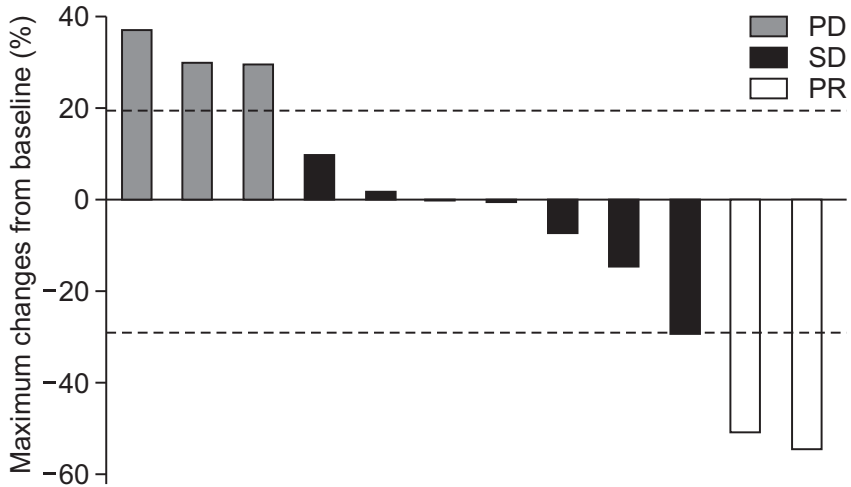

Figure 3. Best change in measurable lesion size from baseline for 12 patients with evaluable indicator lesions: waterfall plot. PD: progressive disease; SD: stable disease; PR: partial remission.

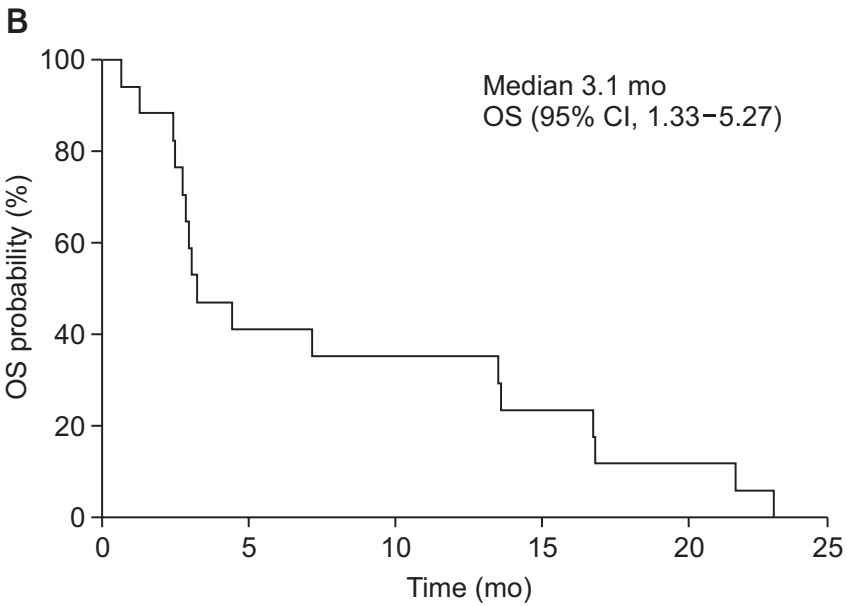

Figure 2. Survival analyses. (A) Kaplan-Meier progression-free survival (PFS) curve. (B) Kaplan-Meier overall survival (OS) curve. CI: confidence interval. 
Table 3. Toxicity profile

\begin{tabular}{|lccc|}
\hline \multicolumn{1}{|c}{ Toxicity } & Grade 1 & Grade 2 & Grade 3-4 \\
\hline Hematologic & $1(5.9)$ & - & - \\
Neutropenia & - & - & - \\
\hline Febrile neutropenia & $5(29.4)$ & $4(23.5)$ & - \\
\hline Anemia & $1(5.9)$ & - & - \\
\hline Thrombocytopenia & & & \\
Nonhematologic & $4(23.5)$ & $1(5.9)$ & - \\
\hline Nausea & $2(11.8)$ & - & - \\
Vomiting & $3(17.6)$ & $2(11.8)$ & $2(11.8)$ \\
\hline Diarrhea & - & - & - \\
Constipation & $2(11.8)$ & $4(23.5)$ & - \\
\hline Mucositis & - & - & $1(5.9)$ \\
\hline Dizziness & - & - & - \\
\hline Peripheral neuropathy & $4(23.5)$ & - & - \\
\hline Rash & & & \\
\hline
\end{tabular}

Values are presented as number (\%).

used in NSCLC, and the recommended dose is $75 \mathrm{mg} / \mathrm{m}^{2} \mathrm{ev}-$ ery 3 weeks. However, this regimen is associated with a high frequency of neutropenia, so other methods to reduce this toxicity have been required.

Kim et al. ${ }^{20}$ showed that docetaxel plus cisplatin $60 / 60 \mathrm{mg}$ was not inferior to $75 / 60 \mathrm{mg}$ in response rate, and that the reduced combination dosage provides a better safety profile for Korean advanced NSCLC patients. Du et al. ${ }^{21}$ showed that a weekly docetaxel regimen significantly reduced the occurrence of severe neutropenia, including febrile neutropenia. Other recent clinical trials of a weekly docetaxel regimen as first-line chemotherapy also demonstrated that it is a suitable therapy; however, they were carried out on a mixed patient population that included elderly and young patients. Therefore, it was necessary to confirm the efficacy and safety of docetaxel in elderly patients.

Based on this information, we have evaluated the efficacy and safety of a weekly docetaxel regimen in elderly patients with squamous cell lung cancer. In a recent study of a weekly docetaxel regimen ${ }^{21,22}$, they administered docetaxel at 30-40 $\mathrm{mg} / \mathrm{m}^{2}$; however, we designed a study with a dose of $25 \mathrm{mg} /$ $\mathrm{m}^{2}$, which is lower than previous studies, considering the risk of toxicity in elderly patients.

In our data, the median OS and median PFS seemed to be inferior to those of previous studies in terms of efficacy. This is presumably because the low dose of $25 \mathrm{mg} / \mathrm{m}^{2}$ was insufficient for an antitumor effect.

However, in terms of safety, the results were much superior. Toxicities of grade 3 or higher were observed in only two patients, dizziness and diarrhea. In particular, neutropenia, a very common side effect in the 3 -week regimen, was seen in only one patient and could reduce the risk of secondary infections. One interesting point is that the incidence of anemia is higher than the incidence of neutropenia. Other docetaxelrelated clinical studies have reported an incidence of grade 1 or 2 anemia in $73 \%$ to $85 \%^{23}$. Nothing has been revealed for such reasons. There were only 2 dose adjustments and no fatal events related to the side effects of the drug.

Our study has some limitations. First, it was performed as single arm study, so we could not simply compare the results with those of other studies. Second, we recruited study patients with a poor PS who received chemotherapy at only two institutions; therefore, we could only obtain a small number of participants. Third, the interval between the median OS and median PFS was relatively short. This was because most of the patients' performances were underestimated and elderly patients refused active supportive care; some of the patients who had disease progression died shortly after.

Although this 4-weekly docetaxel regimen could be safely used in elderly patients with a poor performance, the efficacy of this regimen was lower than other weekly docetaxel regimens and thus resulted in a worse anti-cancer effect. Nevertheless, in some subgroups that are vulnerable to toxicity, it is possible to treat them safely through this regimen. However, it should be used with caution, especially in patients with a poor PS.

\section{Authors' Contributions}

Conceptualization: Lee HK, Lee SY. Methodology: Lee YS. Data curation: Choi JH, Choi J, Chung SM, Oh JY. Validation: Min KH, Hur GY, Shim JJ, Kang KH. Investigation: Lee HK, Lee SY. Writing - original draft preparation: Choi JH. Writing review and editing: Choi JH. Approval of final manuscript: all authors.

\section{Conflicts of Interest}

No potential conflict of interest relevant to this article was reported.

\section{References}

1. Livingston RB. Current management of unresectable nonsmall cell lung cancer. Semin Oncol 1994;21(5 Suppl 10):411.

2. Schiller JH, Harrington D, Belani CP, Langer C, Sandler A, Krook J, et al. Comparison of four chemotherapy regimens for advanced non-small-cell lung cancer. N Engl J Med 2002;346:92-8.

3. Sekine I, Saijo N. Novel combination chemotherapy in the 
treatment of non-small cell lung cancer. Expert Opin Pharmacother 2000;1:1131-61.

4. Clinical practice guidelines for the treatment of unresectable non-small-cell lung cancer. Adopted on May 16, 1997 by the American Society of Clinical Oncology. J Clin Oncol 1997;15:2996-3018.

5. Borghaei H, Paz-Ares L, Horn L, Spigel DR, Steins M, Ready NE, et al. Nivolumab versus docetaxel in advanced nonsquamous non-small-cell lung cancer. N Engl J Med 2015;373:1627-39.

6. Peters S, Gettinger S, Johnson ML, Janne PA, Garassino MC, Christoph D, et al. Phase II trial of atezolizumab as first-line or subsequent therapy for patients with programmed deathligand 1-selected advanced non-small-cell lung cancer (BIRCH). J Clin Oncol 2017;35:2781-9.

7. Reck M, Rodriguez-Abreu D, Robinson AG, Hui R, Csoszi T, Fulop A, et al. Pembrolizumab versus chemotherapy for PD-L1-positive non-small-cell lung cancer. N Engl J Med 2016;375:1823-33.

8. Fossella FV, DeVore R, Kerr RN, Crawford J, Natale RR, Dunphy F, et al. Randomized phase III trial of docetaxel versus vinorelbine or ifosfamide in patients with advanced nonsmall-cell lung cancer previously treated with platinumcontaining chemotherapy regimens. The TAX 320 Non-Small Cell Lung Cancer Study Group. J Clin Oncol 2000;18:2354-62.

9. Kudoh S, Takeda K, Nakagawa K, Takada M, Katakami N, Matsui K, et al. Phase III study of docetaxel compared with vinorelbine in elderly patients with advanced non-small-cell lung cancer: results of the West Japan Thoracic Oncology Group Trial (WJTOG 9904). J Clin Oncol 2006;24:3657-63.

10. Shepherd FA, Dancey J, Ramlau R, Mattson K, Gralla R, O'Rourke M, et al. Prospective randomized trial of docetaxel versus best supportive care in patients with non-small-cell lung cancer previously treated with platinum-based chemotherapy. J Clin Oncol 2000;18:2095-103.

11. Bansal P, Osman D, Gan GN, Simon GR, Boumber Y. Recent advances in targetable therapeutics in metastatic non-squamous NSCLC. Front Oncol 2016;6:112.

12. Kudo S, Hino M, Fujita A, Igarashi T, Arita K, Niitani H, et al. Late phase II clinical study of RP56976 (docetaxel) in patients with non-small cell lung cancer. Gan To Kagaku Ryoho 1994;21:2617-23.

13. Hainsworth JD, Burris HA 3rd, Litchy S, Morrissey LH, Barton
$\mathrm{JH}$, Bradof JE, et al. Weekly docetaxel in the treatment of elderly patients with advanced nonsmall cell lung carcinoma. A Minnie Pearl Cancer Research Network Phase II Trial. Cancer 2000;89:328-33.

14. Gridelli C, Gallo C, Di Maio M, Barletta E, Illiano A, Maione P, et al. A randomised clinical trial of two docetaxel regimens (weekly vs 3 week) in the second-line treatment of nonsmall-cell lung cancer. The DISTAL 01 study. Br J Cancer 2004;91:1996-2004.

15. Eisenhauer EA, Therasse P, Bogaerts J, Schwartz LH, Sargent $\mathrm{D}$, Ford R, et al. New response evaluation criteria in solid tumours: revised RECIST guideline (version 1.1). Eur J Cancer 2009;45:228-47.

16. Ferlay J, Soerjomataram I, Dikshit R, Eser S, Mathers C, Rebelo $\mathrm{M}$, et al. Cancer incidence and mortality worldwide: sources, methods and major patterns in GLOBOCAN 2012. Int J Cancer 2015;136:E359-86.

17. Rossi A, Gridelli C. Chemotherapy of advanced non-small cell lung cancer in elderly patients. Ann Oncol 2006;17 Suppl 2:ii58-60.

18. Lilenbaum RC. Treatment of advanced non-small-cell lung cancer in special populations. Oncology (Williston Park) 2004;18:1321-5.

19. Midha A, Dearden S, McCormack R. EGFR mutation incidence in non-small-cell lung cancer of adenocarcinoma histology: a systematic review and global map by ethnicity (mutMapII). Am J Cancer Res 2015;5:2892-911.

20. Kim KS, Oh IJ, Ban HJ, Cho HJ, Kwon YS, Kim YI, et al. Comparison of docetaxel/cisplatin dosages of $75 / 60$ and 60/60 $\mathrm{mg} / \mathrm{m}(2)$ for the treatment of non-small cell lung cancer. Exp Ther Med 2012;4:317-22.

21. Du Z, Qing J, Ye H, Zhang Z, Lu J. Effects of weekly dose docetaxel monotherapy schedule for elderly patients with non-small cell lung cancer. Chinese-German J Clin Oncol 2009;8:9.

22. Lilenbaum R, Rubin M, Samuel J, Boros L, Chidiac T, Seigel L, et al. A randomized phase II trial of two schedules of docetaxel in elderly or poor performance status patients with advanced non-small cell lung cancer. J Thorac Oncol 2007;2:306-11.

23. Groopman JE, Itri LM. Chemotherapy-induced anemia in adults: incidence and treatment. J Natl Cancer Inst 1999;91:1616-34. 